\title{
Glomerular structural and functional changes in a high-fat diet mouse model of early-stage Type 2 diabetes
}

\author{
P. Wei ${ }^{1}$ P. H. Lane ${ }^{2}$ J. T. Lane ${ }^{3}$ B. J. Padanilam ${ }^{1}$ - S. C. Sansom ${ }^{1}$ \\ ${ }^{1}$ Department of Cellular and Integrative Physiology, University of Nebraska Medical Center, Omaha, USA \\ 2 Department of Pediatrics, University of Nebraska Medical Center, Omaha, Nebraska, USA \\ ${ }^{3}$ Department of Internal Medicine, University of Nebraska Medical Center, Omaha, Nebraska, USA
}

\section{Abstract}

Aims/hypothesis. Type 2 diabetes often results in diabetic nephropathy, which is preceded by an elevated glomerular filtration rate (GFR). This study was designed to develop a mouse model of Type 2 diabetes and to elucidate the glomerular events in the early stages of diabetic nephropathy.

Methods. Four-week-old mice were fed a normal or high-fat ( $42 \%$ of total calories from fat) diet, and body weight, blood glucose, insulin, leptin, lipids and GFR were monitored from 9 to 21 weeks or longer after the feeding programme. Mesangial cell dedifferentiation was accessed by alpha-smooth muscle actin staining. Glomerular hypertrophy was determined using image analysis with haematoxylin-eosin staining. Matrix deposition was determined by type IV collagen staining. Results. After 9 weeks, mice fed a high-fat diet weighed more than mice fed a normal diet $(30.5 \pm 1.2$ vs $22.3 \pm 0.5 \mathrm{~g}, p<0.05$ ), and mice fed a high-fat diet were hyperinsulinaemic $(283.9 \pm 69.7$ vs $102.9 \pm 36.4 \mathrm{pmol} / \mathrm{l}$, $p<0.05)$, hyperglycaemic $(8.0 \pm 0.6$ vs $6.5 \pm 0.2 \mathrm{mmol} / \mathrm{l}$, $p<0.05)$ and their leptin levels were increased six-fold $(1.48 \pm 0.45$ vs $0.25 \pm 0.03 \mathrm{ng} / \mathrm{ml}, p<0.05)$. After 13 weeks, mice fed a high-fat diet showed hyperfiltration (GFR; $440 \pm 60$ vs $210 \pm 10 \mu \mathrm{l} / \mathrm{min}, p<0.05$ ). During the early stages of diabetic nephropathy, mesangial cell dedifferentiation was evident, shown by increased expression of alpha-smooth muscle actin in the glomeruli. After 9 weeks, mice fed a high-fat diet already demonstrated increased type IV collagen deposition. After 13 weeks, they developed enlarged glomerular tufts compared with those of their age-matched controls.

Conclusions/interpretation. The results of this study suggest that collagen IV deposition precedes the hyperfiltration and enlargement of glomeruli in early-stage diabetic nephropathy. Dedifferentiation of mesangial cells may be associated with collagen IV deposition.

Keywords Diabetic nephropathy - GFR . Glomerulopathy · High-fat diet · Hyperfiltration . Hyperglycaemia $\cdot$ Hyperinsulinaemia $\cdot$ Leptin · Mice - Obesity - Type IV collagen - Type 2 diabetes
Received: 2 February 2004 / Accepted: 4 May 2004 Published online: 27 August 2004

(C) Springer-Verlag 2004

\section{S. C. Sansom (}

Department of Cellular and Integrative Physiology,

University of Nebraska Medical Center,

985850 Nebraska Medical Center, Omaha, NE 68198-5850,

USA

E-mail: ssansom@unmc.edu

Tel.: +1-402-5592919, Fax: +1-402-5594438

\section{Introduction}

More than $40 \%$ of the patients requiring dialysis or kidney transplant therapy in the United States are diabetes mellitus patients [1]. Although Type 2 diabetes is ten times more prevalent than Type 1 diabetes, the progression of renal disease in Type 2 diabetes has been studied less intensively and is not as well understood. Type 2 diabetes, unlike Type 1 diabetes, is a more insidious disorder, diagnosed when the pancreatic beta cells can no longer secrete enough insulin to overcome insulin resistance, resulting in a hyperglycaemic status. However, it is now known that Type 2 diabetes is pre- 
ceded by a 5- to 10-year phase of metabolic dysfunction referred to as "insulin resistance syndrome". During this time, the subject is usually obese and the plasma glucose is normal, but blood insulin levels increase to compensate for insulin resistance. Microalbuminuria may occur during this prediabetic phase when it is associated with increased cardiovascular mortality.

A landmark longitudinal study of the Pima Indians of Arizona revealed new details regarding the progression of renal disease in Type 2 diabetes [2]. In the Pima Indians, Type 2 diabetes develops at an early age and is more prevalent than in any other ethnic population. This study showed that Type 2 diabetic patients, like the Type 1 diabetic population, go through a stage of hyperfiltration, which persists until the development of overt diabetic nephropathy [2]. However, for ethical reasons, the pathogenesis of diabetic nephropathy during the phase of insulin resistance could not be studied with biopsies.

In view of the incompletely understood pathogenesis, additional studies on nephropathy related to Type 2 diabetes are required. While much of the experimental insight into diabetic nephropathy has been obtained from streptozocin-induced Type 1 diabetic animal models, less is known about hyperinsulinaemic models that resemble insulin resistance syndrome and Type 2 diabetes. Several rodent models of hyperinsulinaemia and IGT with renal changes have been developed. Most, however, do not correspond with the human diabetic condition [3,4]. For example, leptin deficiency, which is characteristic of $o b / o b$ mice, is rarely observed in humans [5]. It has been shown by several groups that Type 2 diabetes can be induced in C57BL/6 mice by diet alone, a model more similar to the human condition $[6,7,8]$. These mice, more so than other strains, develop a clear phase of insulin resistance that precedes the high glucose levels that diagnose Type 2 diabetes, observed after 26 weeks on a high-fat/high-carbohydrate diet.

Our objective in the following study was to investigate the glomerular mesangial extracellular matrix accumulation during the early diabetic nephropathy induced by a high-fat diet in $C 57 B L / 6 J$ mice.

\section{Materials and methods}

Animal care and sampling. Male C57BL/6J mice were obtained from the Jackson Laboratory (Bar Harbor, Me., USA) and maintained in the specific pathogen-free facility of the University of Nebraska Medical Center. All experiments were performed according to the guidelines of the Institutional Animal Care and Use Committee of the University of Nebraska Medical Center.

Four-week-old weanling mice were placed on a normal diet or high-fat diet (45\% of total calories from fat; Research Diets, N.J., USA), and were given free access to water, with a 12-h day-night rhythm. In the high-fat diet, fat, protein and carbohydrates represent $45 \%, 20 \%$ and $35 \%$ of the total calories, respectively. In the normal diet, fat, protein and carbohydrates represent $10 \%, 20 \%$ and $70 \%$ of the total calories. Upon initiation of the diets, and one day before the mice were killed, weight and blood samples were obtained the morning after an overnight fast (clean cages and bedding, no food, free access to water). Blood samples were withdrawn retro-orbitally under inhalation anaesthesia induced by isoflurane. Blood insulin and leptin levels were measured using an ELISA method according to the manufacturer's instructions (Crystal Chem, Ill., USA). Blood glucose was measured using an Accu-Chek Glucometer (Roche Diagnostic Corporation, Ind., USA). Blood triglyceride, total cholesterol, HDL cholesterol and LDL cholesterol were all measured by an enzymatic-colorimetric method according to the manufacturer's instructions (Pointe Scientific, Mich., USA).

Measurement of GFR. After placing the mice on a normal or high-fat diet for a period of 9, 13, 17 or 21 weeks, the GFR was determined under anaesthesia and the mice were killed. GFR was measured by the FITC-labelled inulin method as previously described by this laboratory [9] and others [10]. In brief, mice were anaesthetised with Inactin $(0.14 \mathrm{mg} / \mathrm{g}$ body weight), and a tracheal tube was inserted. Catheters were inserted in the bladder, jugular vein and carotid artery. The catheter lines were covered with foil to shield the FITC-inulin (Sigma-Aldrich, Mo., USA) from the light. The mean arterial blood pressure was monitored using a Harvard Apparatus pressure transducer. Mice with a mean arterial blood pressure of less than $80 \mathrm{~mm} \mathrm{Hg}$ were not used for further experimentation, as GFR fails to autoregulate below this value. Mice were infused with a physiological saline solution containing (in mmol): $145 \mathrm{NaCl}, 5 \mathrm{KCl}, 10 \mathrm{HEPES}$, and 1\% FITC-inulin $(\mathrm{pH} 7.4)$, at a rate of $16 \mu \mathrm{l} \cdot \mathrm{g}$ body weight ${ }^{-1} \cdot \mathrm{h}^{-1}$. Urine was collected for 1 hour subsequent to a 1-hour equilibration period. At the end of the collecting period, blood was withdrawn from the carotid artery. The urine and plasma concentrations of FITC-inulin were measured by the emitted fluorescence using a microplate reader. GFR was calculated as the urinary flow rate $\times$ the concentration of inulin in the urine / the concentration of inulin in the plasma.

Histological analysis. For histological analyses, the mice were killed, the complete kidneys were rapidly removed, fat and non-kidney tissue were trimmed, and the kidneys were weighed. Coronal cross-sections containing the hilus were removed, immediately placed in $10 \%$ neutral buffered formalin and embedded in paraffin. Sections of $5 \mu \mathrm{m}$ thickness were mounted on glass slides and stained with (i) haematoxylin and eosin for general assessment of histology, or (ii) immunohistochemical reagents for detecting alpha-smooth muscle actin and collagen type IV.

Previously described procedures were used in immunohistochemical studies [11]. Briefly, sections were deparaffinised and rehydrated, and endogenous peroxidase was quenched with $3 \%$ $\mathrm{H}_{2} \mathrm{O}_{2}$ for $30 \mathrm{~min}$. Sections were incubated with $10 \%$ horse serum to prevent non-specific binding. The sections were then incubated in mouse anti-smooth muscle actin (clone 1A4; NeoMarkers, Calif., USA) or mouse anti-collagen IV (Ab-2; Oncogene Research Products, Calif., USA) overnight at $4{ }^{\circ} \mathrm{C}$. After three rinses with PBS for $15 \mathrm{~min}$, the sections were incubated with HRPconjugated anti-mouse secondary antibody for 1 hour at room temperature. Sections were rinsed again with PBS and then detected using DAB substrate. Positive and negative controls with respective primary antibodies were applied for each staining.

After each staining, glomeruli were photographed using the MagnaFire 2.1 image processing system. In each slide of a renal section, glomeruli with vascular poles were used for image analysis using Openlab 3.5 software (Improvision, Mass., USA). Four to six mice in each group and 15 to 20 glomeruli in each kidney were analysed. An investigator masked to sample identity performed the image analysis. 
Statistical analysis. All data are presented as means \pm SE. SigmaStat (version 3.00) was used for statistical analysis. Results of age-matched groups were compared using the unpaired $t$ test.

\section{Results}

Figure 1 shows the mean weights over time of mice on a normal or high-fat diet. The diet was started immediately upon weaning at 4 weeks of age, and the weight was monitored at 4-week intervals until the

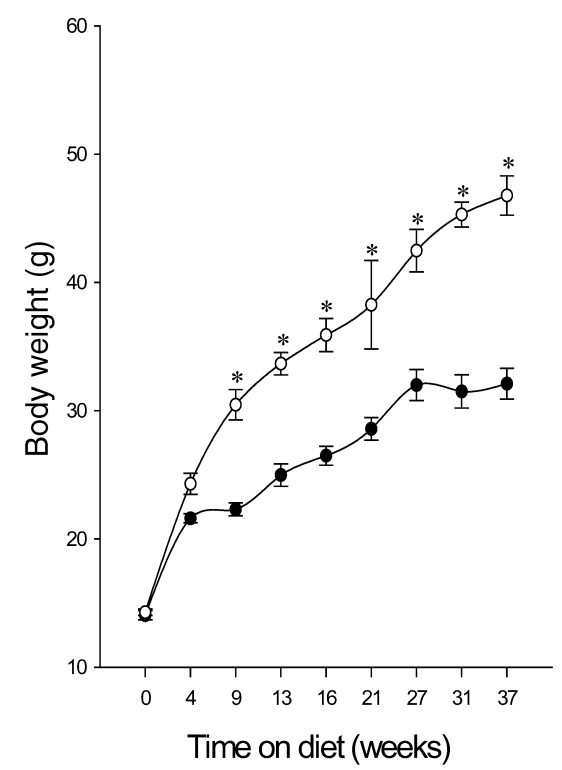

Fig. 1. Plots of body weight over time in mice on a normal (closed circles) or high-fat (open circles) diet. The diet was started at the time of weaning at 4 weeks of age. ${ }^{*} p<0.05$ vs age-matched controls (normal diet) mice were 41 weeks old. As shown, the mice on a high-fat diet weighed significantly more than agematched controls after only 9 weeks, and weighed at least $8 \mathrm{~g}$ more than controls in the later stages.

Change over time of the mean fasting blood glucose and insulin levels are illustrated in Figure 2. As shown in Figure 2a, the insulin concentrations of mice on a normal diet remained between 30 and $100 \mathrm{pmol} / \mathrm{l}$ for the duration of the study. However, the fasting blood insulin levels increased significantly from $45 \mathrm{pmol} / \mathrm{l}$ to $280 \mathrm{pmol} / \mathrm{l}$ after only 9 weeks on a highfat diet. The insulin levels of the mice fed a high-fat diet continued to increase to a peak of approximately $1000 \mathrm{pmol} / \mathrm{l}$. The fasting blood glucose levels (Fig. 2b) in the mice fed a normal diet remained between 5.8 and $7.0 \mathrm{mmol} / \mathrm{l}$ for the duration of the study. Fasting blood glucose levels for the mice fed a high-fat diet were significantly elevated to $8.0 \mathrm{mmol} / \mathrm{l}$ after 9 weeks, which indicated the start of the hyperglycaemic stage.

The concentrations of leptin, triglyceride, total cholesterol, HDL cholesterol and LDL cholesterol in the blood, determined in the mice on a normal or high-fat diet for 9, 13, 16 and 21 weeks, are reported in Table 1 . The leptin concentration, which directly reflects the amount of body fat $[12,13]$, increased sixfold after only 9 weeks on the high-fat diet, and increased to levels 20- to 50-fold greater than normal in the latter stages. Plasma triglyceride and total cholesterol increased after 9 weeks of high-fat feeding, and remained at high levels in the latter stages.

Figure 3 illustrates the mean GFR of mice given a normal or high-fat diet for 9 to 21 weeks. The GFR of the mice on a normal diet was consistently between 190 and $250 \mu \mathrm{l} / \mathrm{min}$ for the duration of the study. The

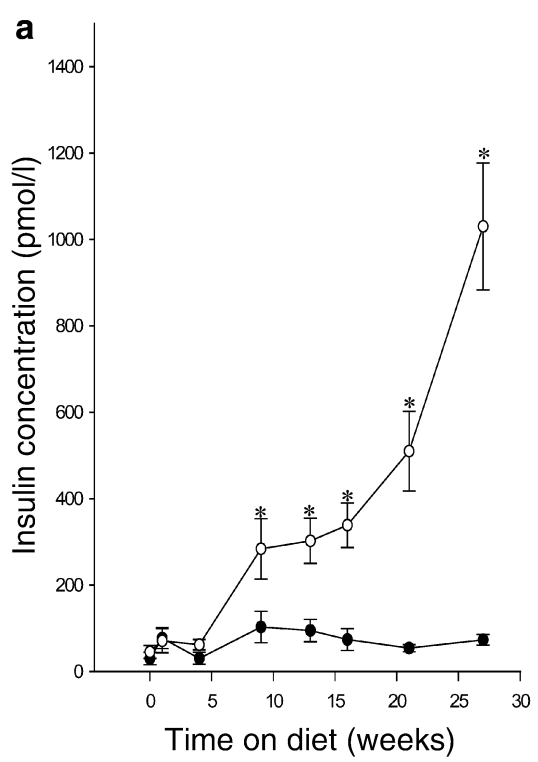

Fig. 2. Plots of fasting blood insulin (a) and glucose (b) concentrations over time in mice on a normal (closed circles) or high-fat (open circles) diet. Concentrations of insulin and

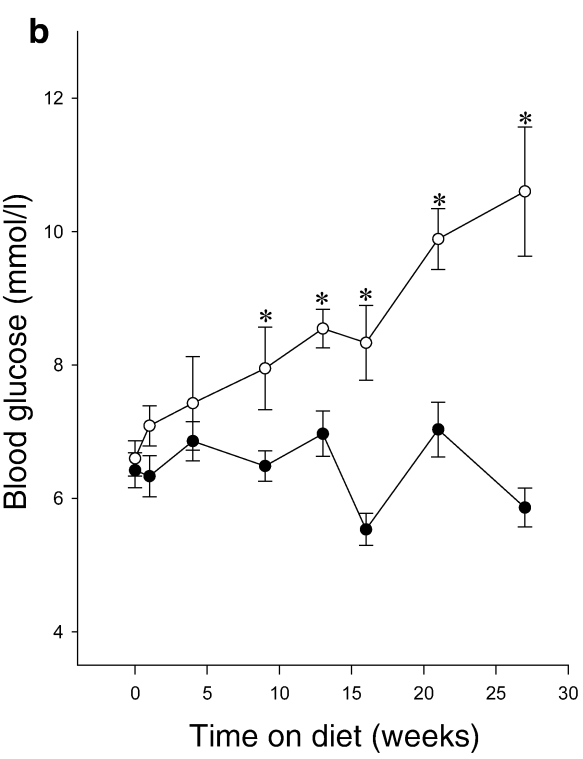

blood glucose increased significantly, and remained elevated after 9 weeks on a high-fat diet. $* p<0.05$ vs age-matched controls (normal diet) 
Table 1. Lipid profile

\begin{tabular}{|c|c|c|c|c|c|c|c|}
\hline $\begin{array}{l}\text { Diet } \\
\text { (weeks) }\end{array}$ & $\begin{array}{l}\text { Age } \\
\text { (weeks) }\end{array}$ & $\begin{array}{l}\text { Number } \\
\text { of mice }\end{array}$ & $\begin{array}{l}\text { Leptin } \\
(\mathrm{ng} / \mathrm{ml})\end{array}$ & $\begin{array}{l}\text { Triglycerides } \\
(\mathrm{mmol} / \mathrm{l})\end{array}$ & $\begin{array}{l}\text { Total cholesterol } \\
(\mathrm{mmol} / \mathrm{l})\end{array}$ & $\begin{array}{l}\text { HDL cholesterol } \\
(\mathrm{mmol} / \mathrm{l})\end{array}$ & $\begin{array}{l}\text { LDL cholesterol } \\
(\mathrm{mmol} / \mathrm{l})\end{array}$ \\
\hline ND (9) & 13 & 7 & $0.25 \pm 0.03$ & $0.50 \pm 0.05$ & $2.55 \pm 0.28$ & $1.91 \pm 0.05$ & $0.35 \pm 0.06$ \\
\hline ND (13) & 17 & 9 & $0.77 \pm 0.30$ & $0.63 \pm 0.11$ & $2.36 \pm 0.24$ & $1.94 \pm 0.03$ & $0.32 \pm 0.07$ \\
\hline HF (13) & & 15 & $16.15 \pm 2.10^{\mathrm{a}}$ & $1.36 \pm 0.15^{\mathrm{a}}$ & $4.48 \pm 0.22^{\mathrm{a}}$ & $2.08 \pm 0.03^{\mathrm{a}}$ & $0.44 \pm 0.05^{\mathrm{a}}$ \\
\hline ND (16) & 20 & 11 & $0.47 \pm 0.15$ & $0.70 \pm 0.10$ & $2.51 \pm 0.10$ & $1.92 \pm 0.08$ & $0.29 \pm 0.05$ \\
\hline HF (21) & & 5 & $23.58 \pm 0.92^{\mathrm{a}}$ & $1.19 \pm 0.10^{\mathrm{a}}$ & $5.17 \pm 0.51^{\mathrm{a}}$ & $3.77 \pm 0.21^{\mathrm{a}}$ & $0.27 \pm 0.06$ \\
\hline
\end{tabular}

ND, normal diet; HF, high-fat diet; a $p<0.05$ vs age-matched controls (ND), determined by unpaired $t$ test

Table 2. Effects of a high-fat diet on the size of glomeruli

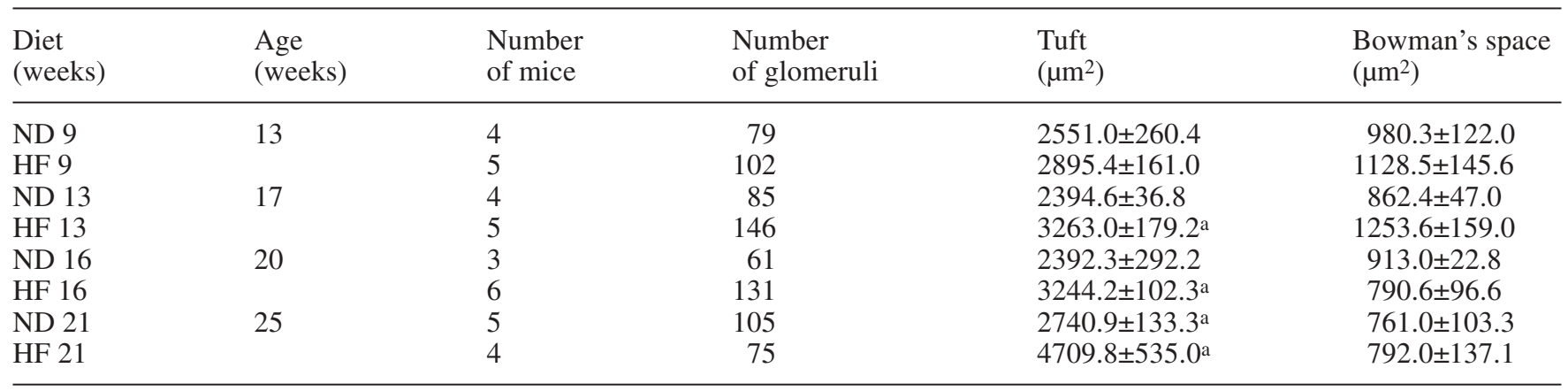

$\mathrm{ND}$, normal diet; HF, high-fat diet; a $p<0.05$ vs age-matched controls (ND), determined by unpaired $t$ test

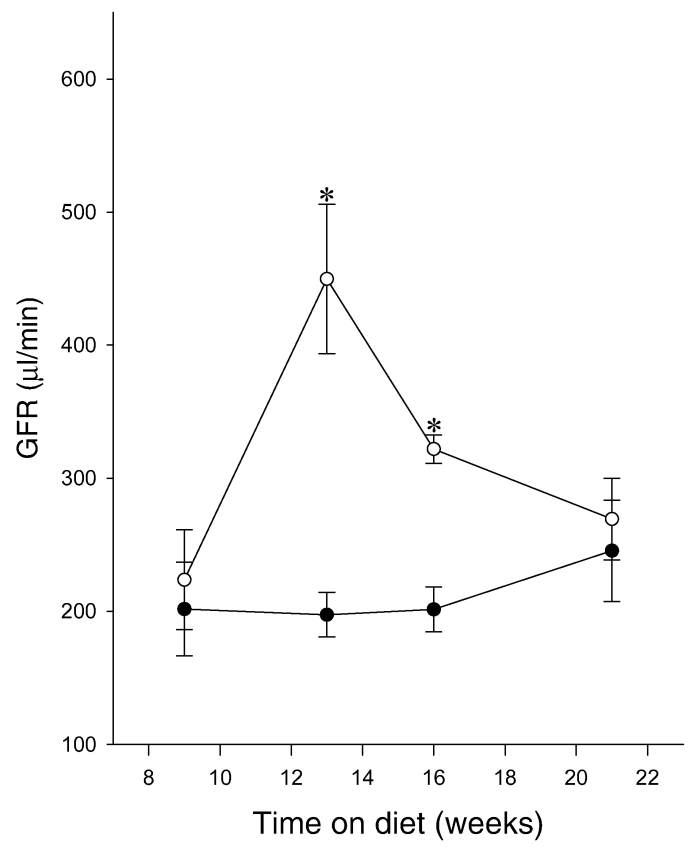

Fig. 3. Plots of GFR over time of mice fed a normal (closed circles) or high-fat (open circles) diet. The GFR of the mice was normal after 9 weeks on a high-fat diet, but then increased more than two-fold after 13 weeks and declined back to normal after 21 weeks. ${ }^{*} p<0.05$ vs age-matched controls (normal diet)
GFR of the mice on the high-fat diet was normal after 9 weeks, then increased by more than $100 \%$ after 13 weeks, and then gradually declined towards normal after 21 weeks.

Haematoxylin-eosin staining was performed on renal sections taken from the mice on a normal diet and the mice on a high-fat diet for $9,13,16$ and 21 weeks. As shown in the representative glomeruli in renal sections of mice given a normal diet (Fig. 4), glomerular (tuft) size was constant from 9 to 21 weeks. However, as shown in Figure 4 and Table 2, glomerular tuft size of the mice fed a high-fat diet gradually increased after 9 weeks, was significantly different after 13 weeks, and almost doubled in size after 21 weeks.

Mesangial cell dedifferentiation was determined by the degree of immunohistochemical staining of alphasmooth muscle actin. As shown in Figure 5, staining for alpha-smooth muscle actin in glomeruli increased after 9 weeks on a high-fat diet, and was even more evident after 16 weeks. The mesangial cell dedifferentiation corresponded with the increased glomerular size. In the mice fed a high-fat diet, positive staining was observed in the vascular pole of glomeruli, as opposed to in the intra-glomerular area as observed in mice on a normal diet. 

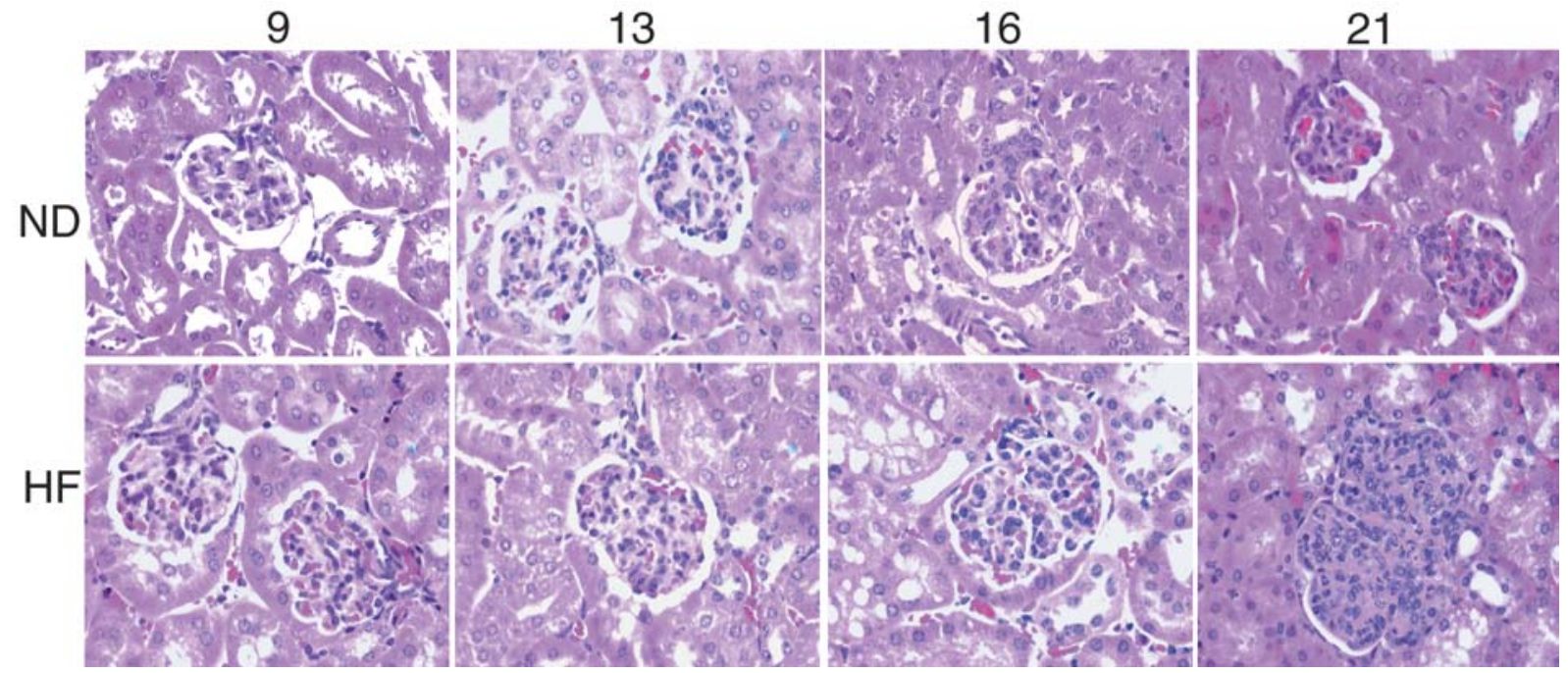

Fig. 4. Haematoxylin-eosin staining of representative renal sections, illustrating glomerular size in mice fed a normal diet (ND) or a high-fat diet (HF) for 9, 13, 16 and 21 weeks. Glom-

erular hypertrophy was evident in mice after 13 weeks on a high-fat diet. Magnification: $\times 400$

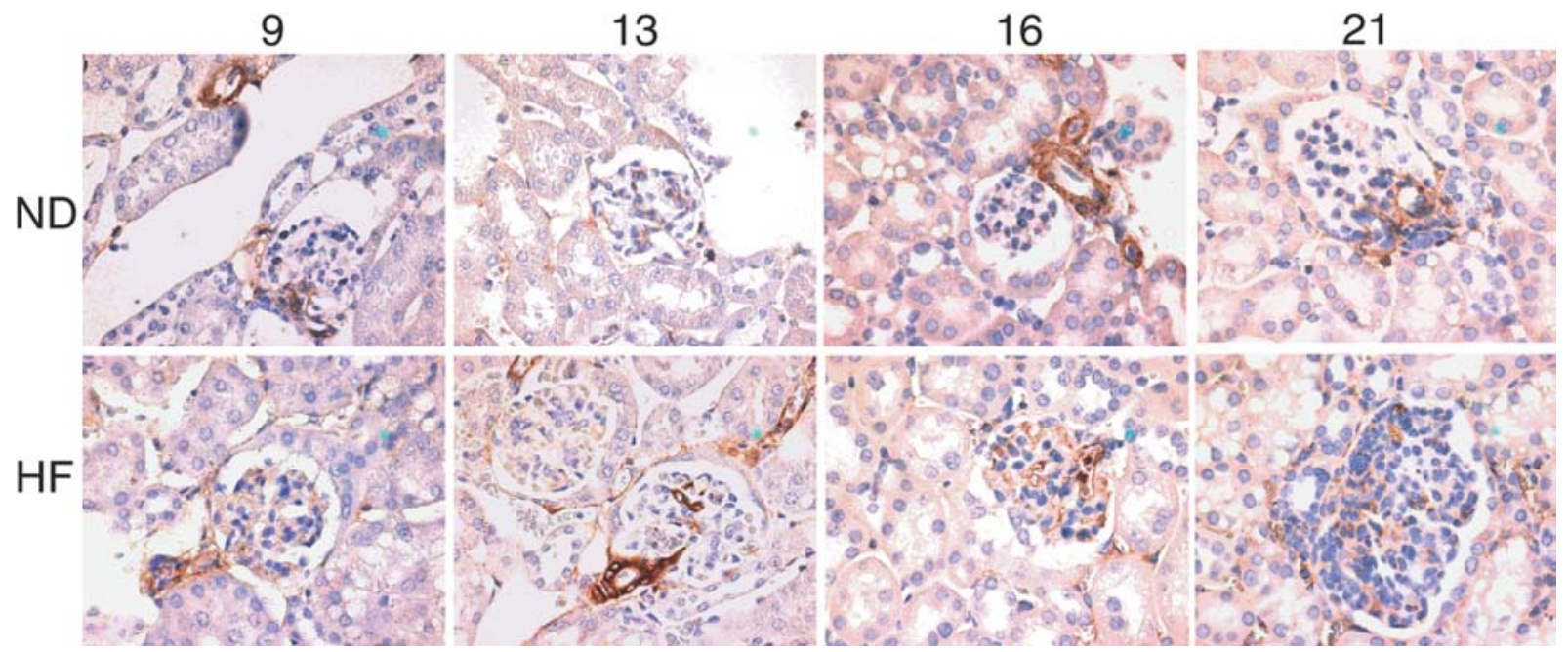

Fig. 5. Mesangial cell dedifferentiation shown by alphasmooth muscle actin staining in glomeruli from mice fed a normal diet (ND) or a high-fat diet (HF) after 9, 13, 16 and 21 weeks. An increase in alpha-smooth muscle actin in the glomeruli was evident in mice fed a high-fat diet. Magnification: $\times 400$

As shown in Figure 6, collagen IV deposition, a measure of matrix deposition, increased after only 9 weeks in the glomeruli from mice on a high-fat diet, and continued to increase from 13 to 21 weeks. These results show that matrix deposition is markedly elevated in early-stage diabetic nephropathy in Type 2 diabetes and that it even precedes the increase in glomerular size.

\section{Discussion}

The results of this study show that glomerular collagen deposition was increased after weanling mice were placed on a high-fat diet for only 9 weeks. The collagen deposition occurs during the period of insulin resistance and precedes glomerular hypertrophy and hyperfiltration previously demonstrated in other animal models of Type 2 diabetes as well as in the Type 2 diabetic Pima Indians.

Mouse model of Type 2 diabetes. Several rodent models have been used to investigate the nephropathy associated with Type 2 diabetes. However, the very complex aetiology of Type 2 diabetes makes it difficult to perfectly mimic this disorder [3]. It is well known that obesity leads to a high incidence of Type 2 diabetes, but the aetiology is not clearly understood. In the present study, we used a simple protocol of supplying mice with high-fat food to elevate caloric consumption. This diet-induced mouse model of 


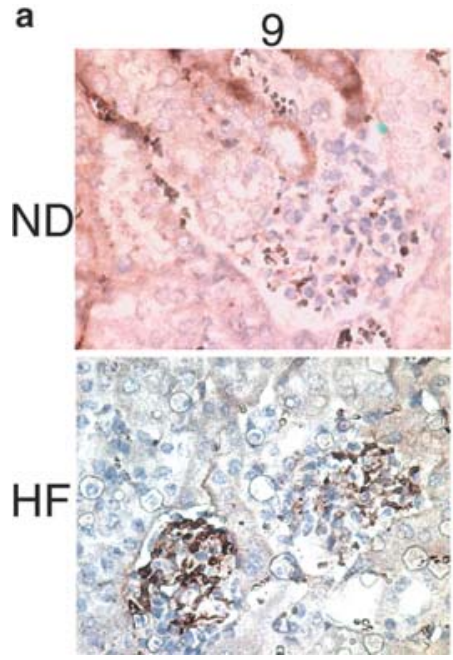

b Negative control
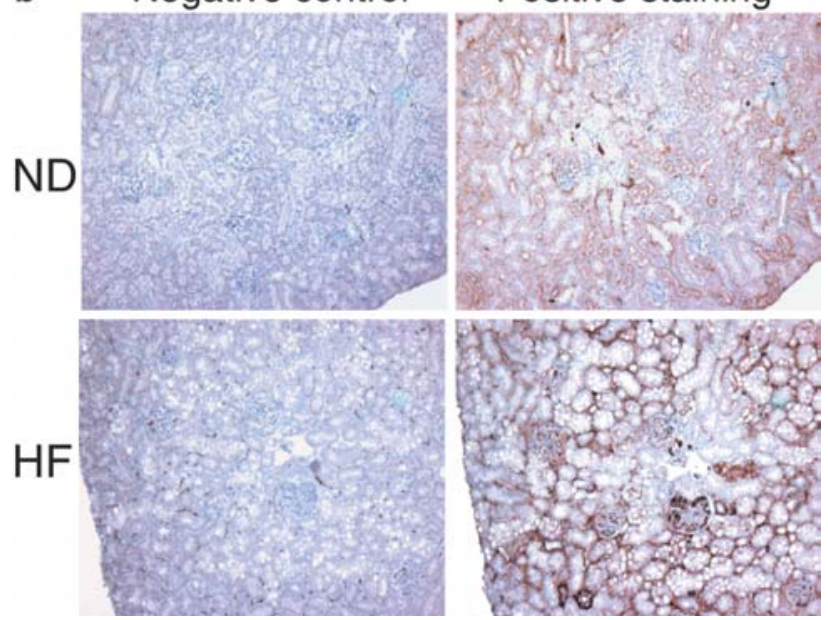

Fig. 6. Collagen IV staining in representative renal sections. a. In mice fed a normal diet (ND), collagen IV was slightly expressed in the glomeruli. In mice on a high-fat diet (HF), collagen IV deposition was elevated after 9 weeks, though glomerular size was normal. Collagen IV deposition continued to increase, along with the size of glomerular tufts in mice on a high-fat diet after 13 to 21 weeks. Magnification: $\times 400$. b. Negative staining controls without anti-collagen IV primary antibody, and positive controls using renal tubule staining. Magnification: $\times 100$

Type 2 diabetes was previously demonstrated in the $C 57 B L / 6 J$ strain by other investigators [6]. When compared with the $A / J$ mouse strain, the $C 57 B L / 6 J$ mice were more prone to early hyperinsulinaemia and hyperglycaemia. These studies were consistent with the notion that a strong genetic component in conjunction with obesity is involved in the development of Type 2 diabetes. This model, therefore, is very similar to the human condition, which is thought to involve a combination of lifestyle and genetics factors.

Besides hyperinsulinaemia, insulin resistance syndrome and diabetes in humans are characterised by severe dyslipidaemia, an important risk factor in the
16

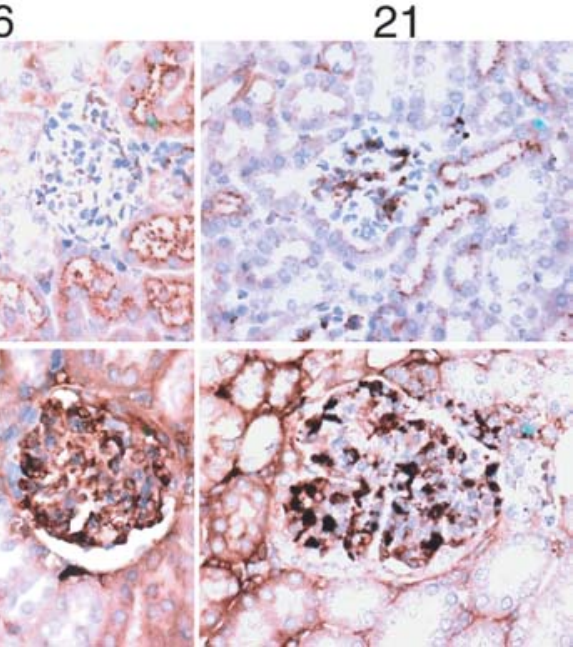

development of atherosclerosis and glomerulosclerosis [14]. However, the lipid profile of the mice is somewhat different from the changes observed in humans. The lipid profile of human Type 2 diabetic patients is characterised by elevated serum triglyceride and VLDL levels and reduced HDL cholesterol levels $[15,16]$. In this study, we found that both plasma triglycerides and total cholesterol were elevated in the hyperinsulinaemic stage. However, compared with the lipid profile in humans, the triglyceride concentration $(0.76 \mathrm{mmol} / \mathrm{l})$ was still at a desirable level [17]. Moreover, unlike in the human condition, HDL cholesterol increased in this diabetic mouse model.

A recent study by Schafer et al. also measured total triglyceride and cholesterol concentrations in C57BL/6 mice on a regular or high-fat diet for 8 weeks [18]. The Schafer study showed that the triglyceride concentrations in the mice fed a high-fat diet were much higher than those in the mice given a normal diet $(1.17 \mathrm{mmol} / \mathrm{l}$ vs $0.74 \mathrm{mmol} / \mathrm{l})$. Our data showed a comparable percentage increase in triglyceride levels in the mice fed a high-fat diet $(0.76 \mathrm{mmol} / \mathrm{l}$ vs $0.45 \mathrm{mmol} / \mathrm{l})$. The elevated basal triglyceride concentrations in the Schafer study may reflect the age of the mice, which was 17 weeks in the Schafer study compared with 13 weeks in our study. The difference in cholesterol levels in the Schafer study (normal diet, $1.95 \mathrm{mmol} / \mathrm{l}$; highfat diet, $4.00 \mathrm{mmol} / \mathrm{l}$ ) was very comparable to the difference in cholesterol after 9 weeks of our study (normal diet, $2.55 \mathrm{mmol} / \mathrm{l}$ and high-fat diet, $3.57 \mathrm{mmol} / \mathrm{l}$ ). We are unaware of another study that has measured HDL cholesterol and LDL cholesterol after administering a high-fat diet to $C 57 B L / 6$ mice. However, our baseline values (13-week-old mice fed a normal diet) of $1.91 \mathrm{mmol} / \mathrm{l}$ for HDL cholesterol and $0.35 \mathrm{mmol} / \mathrm{l}$ for LDL cholesterol were similar to the values of $1.74 \mathrm{mmol} / \mathrm{l}$ and $0.51 \mathrm{mmol} / \mathrm{l}$ found by Maugeais et al. in $C 57 B L / 6$ mice [19].

Leptin is a $16-\mathrm{M}_{\mathrm{r}}$ hormone that is produced mainly in adipocytes of white fat [20]. Leptin was also measured by Schafer et al. [18] before and after feeding 
C57BL/6 mice a high-fat diet. The leptin concentration of $2.2 \mathrm{ng} / \mathrm{ml}$ in mice given a normal diet was greater than the value of $0.25 \mathrm{ng} / \mathrm{ml}$ for the mice fed a normal diet in our study, probably because the mice of the Schafer study were 4 weeks older and weighed $11 \mathrm{~g}$ more. However, the increase in leptin values after 8 weeks of high-fat feeding was comparable to our results.

There is a strong positive correlation between serum leptin levels and overall abundance of adipose tissue $[12,13,21]$. While TGF $\beta$ was not assessed in this study, it has been shown by previous investigators that leptin induces TGF $\beta 1$ expression in glomerular endothelial cells [22] and increases mRNA levels of $T G F \beta$ type II receptors on glomerular mesangial cells [23]. The consequence of this paracrine TGF $\beta$ system is an increase in extracellular matrix deposition, proteinuria, and eventually glomerulosclerosis [22]. Since there was a dramatic increase of blood leptin levels in our study, it will be important to determine in future studies whether leptin can mediate mesangial cell dedifferentiation and accumulation of extracellular matrix.

Dedifferentiation of mesangial cells. The glomerular mesangial cell may have several important beneficial functions in the normal glomerulus. These include the production of growth factors to allow normal cell turnover, the provision of structural support for the capillaries via the production of mesangial matrix, and the modulation of glomerular haemodynamics via their contractile properties. However, in various types of glomerular injury, the mesangial cell may acquire characteristics of a myofibroblast, which may in fact be injurious to the glomerulus. In human glomerulogenesis, mesangial cells gradually lose fetal phenotypes identified by alpha-smooth muscle actin [24]. However, with certain pathogenic stimulators, such as platelet-derived growth factor, mesangial cells may acquire smooth-muscle-like properties, characterised by the de novo expression of alpha-smooth muscle actin, and by the development of fibroblast-like properties, characterised by the production of interstitial collagens in addition to normal mesangial matrix constituents [25]. In our study, expressed alpha-smooth muscle actin in glomeruli indicated the dedifferentiation of mesangial cells, which may be responsible for the deposition of collagen IV in early diabetic nephropathy.

Hyperfiltration in Type 2 diabetes. After developing overt diabetes, the pathological sequences in the progression of nephropathy in Type 2 diabetes seem to follow the same general pattern as in Type 1 diabetes [26]. Hyperfiltration has been shown to be a critical event in the early stages of Type 1 diabetes and is strongly associated with the eventual development of albuminuria and diabetic nephropathy. However, it has been difficult to compare the early pathological transformations of Type 1 diabetes, which has a relatively rapid onset, with those of Type 2 diabetes, which is characterised by more gradual renal changes as the blood glucose levels slowly elevate.

Because hyperfiltration was readily observed in models of Type 1 diabetes, in which insulin levels are diminished, it was presumed that high glucose and its metabolic consequences were the main contributing factors $[27,28]$. The connection between high glucose and hyperfiltration was demonstrated in a previous study showing that hyperfiltration was directly correlated with high $\mathrm{HbA}_{1} \mathrm{c}$ measurements in Type 1 diabetic patients [29]. Other groups studying models of insulin resistance status in the Rhesus monkey and in dogs fed a high-fat diet have found increased GFR [30] associated with glomerular hypertrophy [31]. Thus, in some cases of Type 2 diabetes, glomerular hypertrophy and hyperfiltration may be the result of the high insulin, triglyceride or leptin levels in the insulin resistance status.

It is still possible that hyperfiltration is correlated with hyperglycaemia in human Type 2 diabetes. In the longitudinal study of Type 2 diabetic Pima Indians, hyperfiltration, slightly evident $(10 \%$ greater than normal) with an $\mathrm{HbA}_{1} \mathrm{c}$ of $6.3 \%$ (control $5.9 \%$ ), became more pronounced as the blood glucose levels increased [2]. Thus, it is possible that hyperfiltration is the product of the average elevated blood glucose concentration and the time of exposure to this concentration. In Type 2 diabetes, even though the fasting blood glucose values are mildly elevated, the longterm exposure of slightly elevated basal glucose concentrations may have the same effect on the kidneys as shorter-term exposure to the higher glucose levels of Type 1 diabetes.

Hyperinsulinaemia and glomerular hypertrophy. Glomerular hypertrophy, invariably associated with diabetic nephropathy, is often observed along with hyperfiltration and hyperglycaemia in cases of Type 1 diabetes. In Type 1 diabetes, most longitudinal studies conclude that glomerular hypertrophy is associated with hyperfiltration or albuminuria [32].

It is possible that in Type 2 diabetes, glucose supplies the assault on the renal glomeruli in the same manner as in Type 1 diabetes. However, in Type 2 diabetes, other factors, such as insulin, leptin or lipids may also play a role in the early development of glomerular hypertrophy. The suggestion that hyperinsulinaemia alone can result in glomerular hypertrophy is supported by several studies. Abrass et al. showed that insulin affects mesangial matrix deposition in rat mesangial cells in vitro [33]. Hotta et al. found that glomerular volume was correlated with fasting insulin levels in non-diabetic patients with glomerulosclerosis [34]. In obese Zucker rats, Michel et al. showed that reducing insulin production with acarbose reduced 
mesangial expansion [35]. Thus, the high insulin levels in early-stage Type 2 diabetes mellitus may evoke glomerular hypertrophy, whereas the slightly elevated blood glucose levels may be the cause of hyperfiltration. However, in Type 1 diabetes, findings showed that intensive control of blood glucose by insulin treatment prevented the development and slowed the progression of diabetic kidney disease by $50 \%$ [36]. Thus, the exact role of insulin in the development of diabetic nephropathy still needs more intensive investigation.

Another pathogenic component of the early hyperinsulinaemic stage of Type 2 diabetes is an increase in levels of angiotensin II. While renin levels were not assessed in this study, it has been well established that the renin-angiotensin II axis is elevated in states of prediabetic obesity [37, 38]. Angiotensin II, a growth factor like insulin, may also stimulate glomerular hypertrophy [39]. As reported in a previous study, a combination of glucose, insulin and angiotensin II may conspire to produce an accumulation of mesangial matrix long before the diagnosis of overt diabetes [33].

It is clear that renal cells, like all cells, are adapting to several endocrine and paracrine factors during early-stage Type 2 diabetes. Regardless of whether high insulin, leptin, angiotensin II, or long-term exposure to slightly elevated blood glucose levels lead the assault on renal cells during early-stage Type 2 diabetes, this study showed that collagen IV deposition and glomerular hypertrophy precede hyperfiltration. We conclude that measures to prevent renal disease should be initiated at a very early stage in Type 2 diabetes.

Acknowledgements. This work was supported by a grant from the National Institute of Diabetes and Digestive and Kidney Disease (NIHRO1DK-49561; S. C. Sansom), by a Grant-inAid from the American Heart Association (Heartland Affiliate; 0355405Z; S. C. Sansom), and by a grant from the Nebraska Kidney Foundation (P. Wei)

\section{References}

1. US Renal Data System (2001) Excerpts from the USRDS 2001 Annual Data Report: Atlas of end-stage renal disease in the United States. Am J Kidney Dis 38 [Suppl 3]: S1-S248

2. Nelson RG, Bennett PH, Beck GJ et al. (1996) Development and progression of renal disease in Pima Indians with non-insulin-dependent diabetes mellitus. Diabetic Renal Disease Study Group. N Engl J Med 335:16361642

3. Janssen U, Phillips AO, Floege J (1999) Rodent models of nephropathy associated with type II diabetes. J Nephrol 12:159-172

4. Mauvais-Jarvis F, Kulkarni RN, Kahn CR (2002) Knockout models are useful tools to dissect the pathophysiology and genetics of insulin resistance. Clin Endocrinol (Oxf) $57: 1-9$
5. Anania FA (2002) Leptin, liver, and obese mice-fibrosis in the fat lane. Hepatology 36:246-248

6. Surwit RS, Kuhn CM, Cochrane C, McCubbin JA, Feinglos MN (1988) Diet-induced type II diabetes in C57BL/6J mice. Diabetes 37:1163-1167

7. West DB, Boozer CN, Moody DL, Atkinson RL (1992) Dietary obesity in nine inbred mouse strains. Am J Physiol 262:R1025-R1032

8. Muurling M, Jong MC, Mensink RP et al. (2002) A low-fat diet has a higher potential than energy restriction to improve high-fat diet-induced insulin resistance in mice. Metabolism 51:695-701

9. Pluznick JL, Wei P, Carmines PK, Sansom SC (2003) Renal fluid and electrolyte handling in BKCa-beta1-/- mice. Am J Physiol Renal Physiol 284:F1274-F1279

10. Lorenz JN, Gruenstein E (1999) A simple, nonradioactive method for evaluating single-nephron filtration rate using FITC-inulin. Am J Physiol 276:F172-F177

11. Martin DR, Lewington AJ, Hammerman MR, Padanilam BJ (2000) Inhibition of poly(ADP-ribose) polymerase attenuates ischemic renal injury in rats. Am J Physiol Regul Integr Comp Physiol 279:R1834-R1840

12. Friedman JM, Halaas JL (1998) Leptin and the regulation of body weight in mammals. Nature 395:763-770

13. Considine RV, Sinha MK, Heiman ML et al. (1996) Serum immunoreactive-leptin concentrations in normal-weight and obese humans. N Engl J Med 334:292-295

14. Kramer-Guth A, Quaschning T, Greiber S, Wanner C (1996) Potential role of lipids in the progression of diabetic nephropathy. Clin Nephrol 46:262-265

15. Howard BV (1987) Lipoprotein metabolism in diabetes mellitus. J Lipid Res 28:613-628

16. Goldberg IJ (2001) Diabetic dyslipidemia: causes and consequences. J Clin Endocrinol Metab 86:965-971

17. American Diabetes Association (2000) Management of dyslipidemia in adults with diabetes. Diabetes Care 23 [Suppl 1]:S57-S60

18. Schafer K, Halle M, Goeschen C et al. (2004) Leptin promotes vascular remodeling and neointimal growth in mice. Arterioscler Thromb Vasc Biol 24:112-117

19. Maugeais C, Tietge UJ, Broedl UC et al. (2003) Dosedependent acceleration of high-density lipoprotein catabolism by endothelial lipase. Circulation 108:2121-2126

20. Vinay P, Gougoux A, Lemieux G (1981) Isolation of a pure suspension of rat proximal tubules. Am J Physiol 241:F403-F411

21. Schwartz MW, Seeley RJ (1997) Neuroendocrine responses to starvation and weight loss. N Engl J Med 336:1802-1811

22. Wolf G, Hamann A, Han DC et al. (1999) Leptin stimulates proliferation and TGF-beta expression in renal glomerular endothelial cells: potential role in glomerulosclerosis [see comments]. Kidney Int 56:860-872

23. Han DC, Isono M, Chen S et al. (2001) Leptin stimulates type I collagen production in $\mathrm{db} / \mathrm{db}$ mesangial cells: glucose uptake and TGF-beta type II receptor expression. Kidney Int 59:1315-1323

24. Naruse K, Fujieda M, Miyazaki E et al. (2000) An immunohistochemical study of developing glomeruli in human fetal kidneys. Kidney Int 57:1836-1846

25. Johnson RJ, Floege J, Yoshimura A, Iida H, Couser WG, Alpers CE (1992) The activated mesangial cell: a glomerular "myofibroblast"? J Am Soc Nephrol 2:S190-S197

26. Ritz E (1999) Nephropathy in type 2 diabetes. J Intern Med 245:111-126

27. Castellino P, Shohat J, DeFronzo RA (1990) Hyperfiltration and diabetic nephropathy: is it the beginning? Or is it the end? Semin Nephrol 10:228-241 
28. Palm F, Liss P, Fasching A, Hansell P, Carlsson PO (2001) Transient glomerular hyperfiltration in the streptozotocindiabetic Wistar Furth rat. Ups J Med Sci 106:175-182

29. Soper CP, Barron JL, Hyer SL (1998) Long-term glycaemic control directly correlates with glomerular filtration rate in early Type 1 diabetes mellitus before the onset of microalbuminuria. Diabet Med 15:1010-1014

30. Henegar JR, Bigler SA, Henegar LK, Tyagi SC, Hall JE (2001) Functional and structural changes in the kidney in the early stages of obesity. J Am Soc Nephrol 12:12111217

31. Cusumano AM, Bodkin NL, Hansen BC et al. (2002) Glomerular hypertrophy is associated with hyperinsulinemia and precedes overt diabetes in aging rhesus monkeys. Am J Kidney Dis 40:1075-1085

32. Osterby R, Bangstad HJ, Nyberg G, Rudberg S (2001) On glomerular structural alterations in type-1 diabetes. Companions of early diabetic glomerulopathy. Virchows Arch 438:129-135

33. Abrass CK, Spicer D, Raugi GJ (1995) Induction of nodular sclerosis by insulin in rat mesangial cells in vitro: studies of collagen. Kidney Int 47:25-37
34. Hotta O, Taguma Y, Chiba S et al. (1996) Possible relationship between hyperinsulinemia and glomerular hypertrophy in nephrosclerosis. Ren Fail 18:271-278

35. Michel O, Heudes D, Lamarre I et al. (1997) Reduction of insulin and triglycerides delays glomerulosclerosis in obese Zucker rats. Kidney Int 52:1532-1542

36. The Diabetes Control and Complications Trial Research Group (1993) The effect of intensive treatment of diabetes on the development and progression of long-term complications in insulin-dependent diabetes mellitus. N Engl J Med 329:977-986

37. Tuck ML, Sowers J, Dornfeld L, Kledzik G, Maxwell M (1981) The effect of weight reduction on blood pressure, plasma renin activity, and plasma aldosterone levels in obese patients. N Engl J Med 304:930-933

38. Hall JE, Brands MW, Henegar JR (1999) Mechanisms of hypertension and kidney disease in obesity. Ann NY Acad Sci 892:91-107

39. Mori Y, Wakamori M, Miyakawa T et al. (2002) Transient receptor potential 1 regulates capacitative $\mathrm{Ca}(2+)$ entry and $\mathrm{Ca}(2+)$ release from endoplasmic reticulum in B lymphocytes. J Exp Med 195:673-681 